\title{
Orthopaedic Appliances for Leprosy Patients The Fixed Ankle Brace Walker ${ }^{*}$
}

\author{
LUTZ WOLLSTEIN $\ddagger$ \\ Orthopaedic Tech. Master, Schieffelin Leprosy Research Sanatorium, \\ Karigiri, South India \\ JOHN GIRLING \\ Manager, Artificial Limb Workshop. Christian Medical College and Hospital, \\ Vellore, South India
}

\begin{abstract}
The authors describe an appliance, the FAB walker, that has been developed to confirm the proposition that if a plaster-of-Paris walking cast will heal a plantar ulcer, then an appliance that follows the principles of a PoP cast will prevent re-ulceration. The weight distribution principles of the PoP cast are described and how these principles are built into the FAB walker. Details are given of the specially shaped sole which allows the patient to walk with a normal gait, even though the ankle is fully immobilized. The step-by-step measurement taking and the procedures of making the walker are described. The types of foot deformities that benefit from the appliance are listed, as well as other advantages and disadvantages.
\end{abstract}

The main obstacle in the rehabilitation of leprosy patients with badly deformed feet is the continual recurrence of their plantar ulcers. The ulcers heal in a below-knee walking cast of plaster-of-Paris (PoP). Footwear is then given, but in most cases the patient returns to the clinic within 1 to 3 months with re-ulceration. This can be referred to as the "eternal circle of re-ulceration". If the patient's foot could be kept permanently in a PoP cast the re-ulceration would not occur. This was first stated by Price (1961), who wrote: "The recent observations of the effect of plaster casts does [sic], how ever, suggest an effective method of preventing recurrence of ulceration. It is based on the deduction that as the ulcer has healed while the cast was in position, it would remain healed if the cast was left on the limb indefinitely." Various designs of footwear have been developed that have partially followed the PoP design. This footwear has usually included a ridged sole, moulding of the inner sole, and some form of roll (Price, 1960; Ross 1962; Ward, 1964; Girling et al., 1967). None of the designs has included a projection up the leg to immobilize the ankle. For many patients whose feet are not badly deformed this ridged footwear has been sufficient to

* Received for publication July, 1971.

† Sponsored by the Swiss Emmaus Association.

$\neq \mathrm{A}$ detailed illustrated manual describing the step by step manufacture of the FAB walker is obtainable from L. Wollstein, S.L.R.S., P.O., Karigiri, via Katpadi, South India. 
prevent re-ulceration, but for those with more severely deformed feet this has not been the case.

The foot deformities which present the unsolved ulcer problems are: (1) The foot with the completely collapsed tarsal and metatarsal arch (the boat-shaped foot). (2) The grossly inverted or everted foot in which the plantar aspects of the foot are intact, but the ulceration occurs on the medial or lateral border. (3) The grossly absorbed foot, with constant high pressures on the forefoot because of imbalance of the dorsal to the plantar flexors. (4) The ridged arthrodized foot.

The footwear given so far to patients with these types of feet have not prevented re-ulceration. This paper describes a design of footwear incorporated into a brace that follows exactly the basic characteristics of the PoP walking cast.

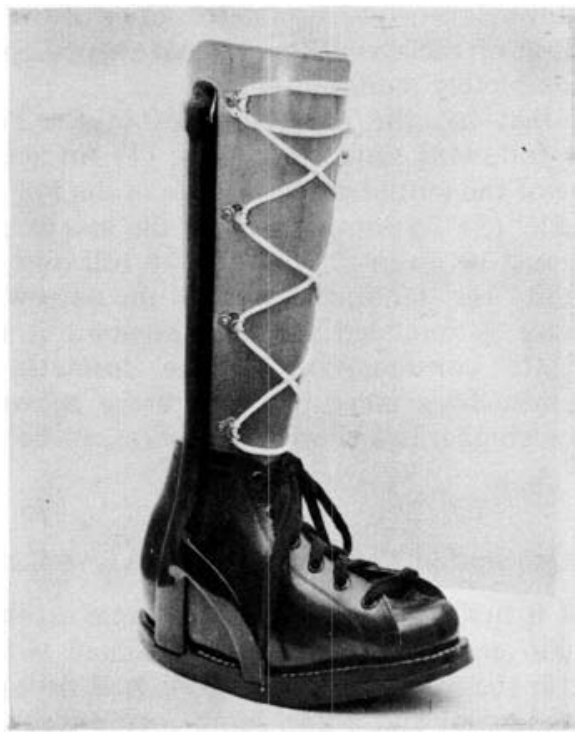

Fig. 1. The fixed ankle brace walker.

This appliance is called the fixed ankle brace (FAB) walker (Fig. 1), and it has been used at the Schieffelin Leprosy Research Sanatorium, Karigiri, and the Christian Medical College and Hospital, Vellore, for the last 3 years. To date, over 100 of these appliances have been issued to patients, and a detailed long-term follow-up is being carried out. What has been observed so far is that the majority of the patients now using the FAB walker are at last free from ulcers, after having suffered many years with the "eternal circle of re-ulceration".

To understand the function of the FAB walker fully we must first of all look into the function and action of the below-knee PoP cast. When a patient has a plantar ulcer a thin dressing is applied over the ulcer, and his leg is put into a PoP cast. There is no microcellular rubber (MCR) in the cast to give moulding or to act as a shock absorber. It must be realized that in a below-knee cast all the weight is taken through the plantar surface of the foot, no weight-bearing being taken on the lateral or medial aspects of the leg. There is, however, one big difference. The pressures placed on the sole of the foot in a PoP cast are very different from those 
normally taken while walking barefoot. While walking in the PoP cast there is very even distribution of pressures over the whole of the plantar surface during the entire weight-bearing phase. These pressures have been measured and are around $0.5 \mathrm{~kg}$ per $\mathrm{cm}^{2}\left(7 \mathrm{~b} / \mathrm{in}^{2}\right)$ (Bauman et al., 1963). It must also be realized that this intermittent pressure also comes on to the ulcer area, yet the ulcer heals. It may even be that controlled intermittent pressure on a wound encourages healing, the theory being that the intermittent pressures on the ulcer act as a pump for the blood supply. If an ulcer will heal with controlled intermittent pressures on it, then it will stay healed under similar controlled intermittent pressures. In addition to the even distribution of weight, the PoP cast prevents localized, high, oblique pressures resulting from deacceleration (heel strike) and acceleration (push off). Further increase of inversion or eversion deformities of the foot are prevented, as well as further collapse of the tarsal bones (boat-shaped foot). The joints of the foot and ankle are completely immobilized.

A walking brace that has the characteristics of the PoP walking cast must necessarily have the following similar qualities: (1) An accurately hard-moulded sole to take the place of the moulded plaster sole in the PoP cast. (2) A method of immobilizing the ankle. (3) To compensate for the loss of ankle movement, some form of rocker bar must be given for the foot to roll over. In the brace this bar must give more stability for standing than does the narrow rocker bar of the PoP cast. (4) As the brace is intended to be permanent it must be cosmetically acceptable, taking into consideration all the cosmetic limitations that the deformed foot presents. To achieve this in a brace is not difficult. In fact by orthopaedic-appliance standards a simple appliance can be made which fulfils all these criteria easily.

\section{Method of Fabrication of a FAB Walker}

The patient's foot is first inspected for danger areas on the sole, i.e., hard scars, prominent bones, skin grafts, etc. These are outlined with an indelible pencil. Malleoli are marked in the same way. A strip of lead or leather is then put down the front of the leg and foot and a thin damp cotton stocking then pulled over it up to the knee. Foot and leg are wrapped in plaster bandage extending to $10 \mathrm{~mm}$ ( $3 / 8$ in) below the head of the fibula. With the patient sitting and the foot in a plantar-grade position the foot is pressed against a sheet of soft foam rubber (Fig. 2). Care must be taken that the leg is at an angle of $90^{\circ}$ to the floor. The plaster cast is then cut off with a knife, cutting down on to the lead or leather strip (Fig. 3 ); the indelible pencil marks will have been transferred to the inside of the plaster cast. The cast is now closed up with one more plaster bandage and filled with plaster cream. A holding and reinforcing rod is then sunk into the plaster; this rod must extend right down to the foot. When the plaster has set the bandage wrap is removed and the cast adapted.

The malleoli are built up with plaster by approximately $6 \mathrm{~mm}(1 / 4 \mathrm{in})$. The tendon Achilles is built up $3 \mathrm{~mm}$ (1/8 in) and the toes built out by at least $25 \mathrm{~mm}$ ( 1 in). The forefoot shape is formed to give a cosmetic shape to the shoe while at the same time giving clearance for the toes. The danger areas on the plantar aspect of the foot are re-marked with indelible pencil (Fig. 4). When the cast is fully dried a thin cotton sock is pulled over it and painted with polyester resin; this is done to reinforce the cast. The marks on the plantar surface will show through the sock reinforcement. These areas are then built up with a layer of 6-mm cork 


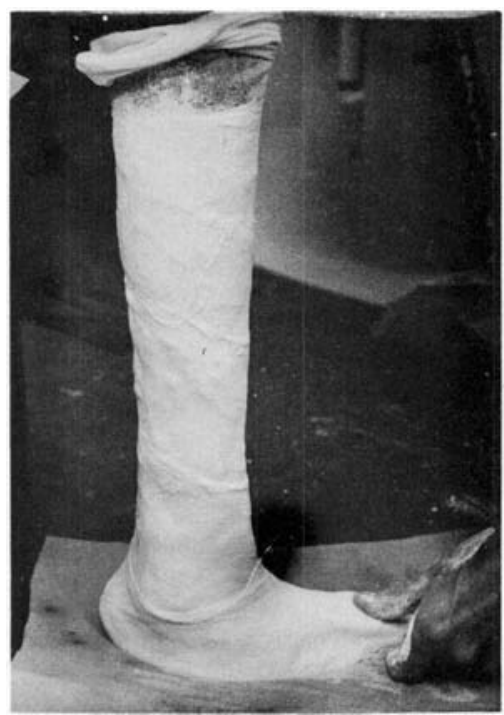

Fig. 2. Taking the plaster cast.

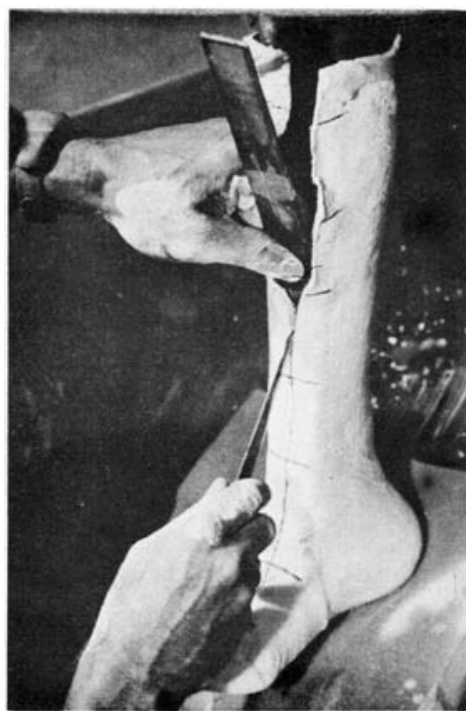

Fig. 3. Cutting off the plaster cast.

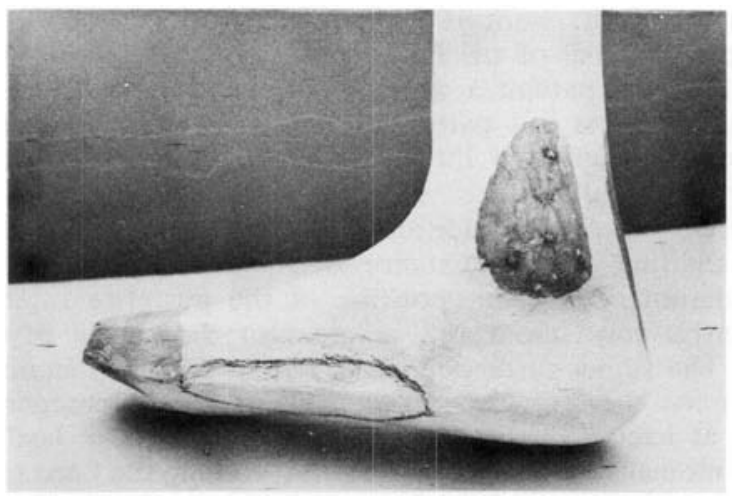

Fig. 4. The adapted plaster cast with the danger area marked.

sheet with the edges blending into the foot shape (Fig. 5). In the finished moulded sole the cork will be replaced by a $6-\mathrm{mm}$ patch of 15 shore microcellular rubber; this MCR patch will accurately mould itself to the minute unevenness of the danger areas. It is not possible to produce such minute moulding in a plaster cast. 


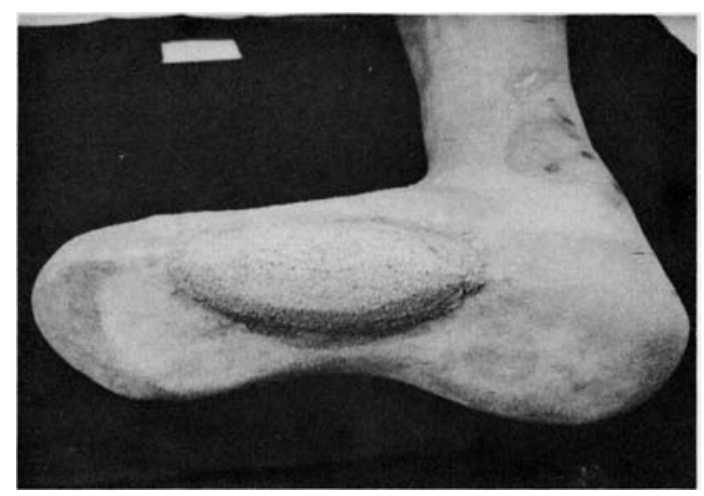

Fig. 5 The cast reinforced with a sock impregnated with polyester resin. The cork build-up over the danger area can be seen.

A vertical bisecting line is now drawn down the lateral aspect of the leg. Thin sole leather is blocked on to the foot, extending up the medial side in the area of the arch. If there is an inversion deformity the leather should also extend up the lateral side. The underside of the blocked leather sole is built up with cork sheet until it is level.

The moulded cork insole serves two purposes: (1) It forms an accurate firm mould to give even distribution of pressure to the patient's foot. (2) The underside is shaped so as to give the bottom shape to the sole of the boot. This bottom-sole shape of the boot is very important, as it has to serve the same function as the rocker bar of the PoP cast. At the same time it must also be so shaped as to allow the patient a smooth uninterrupted gait. Since the patient's ankle is immobilized. the gait pattern is controlled entirely by the bottom-sole shape. The sole is divided into three parts (Fig. 6) viz. (1) Impact-surface. (2) Stance-surface. (3) Toe-off-surface.

The line where the impact-surface joins the stance-surface is called the posterior fulcrum, while the line where the stance-surface joins the toe-off-surface is called the anterior fulcrum. The exact position of the posterior fulcrum and of the anterior fulcrum is very important, as are also the angles of the impact and toe-off-surface. The stance-surface must be flat to give firm standing ability. The impact-surface must curve upwards at an angle of $20^{\circ}$ to compensate for lack of plantar flexion at heel strike and also to prevent excessive heel impact, as this would create a moment around the knee joint, forcing the knee into flexion. The posterior fulcrum will be 2 to $3 \mathrm{~cm}$ behind the lateral vertical bisecting line. The toe-off-surface must also slope upwards to compensate for lack of dorsiflexion. The angle of this must be at least $15^{\circ}$ and the anterior fulcrum should be at, or just posterior to, the metatarsal heads. Care must be taken while building up the cork that the latter vertical line is at $90^{\circ}$ to the stance-surface (Fig. 7). From the anterior view, the shank must lean slightly to the lateral (outer) side (Fig. 8); this will allow for the bowing of the lower leg.

When the cork build-up has been carefully checked, the edges of the moulded leather are trimmed and skived down to blend into the shape of the cast. A blocked leather shank gaiter is put on with a skived anterior overlap and the boot is then built over the foot and the cork sole (Fig. 9). The top edge of the upper of 


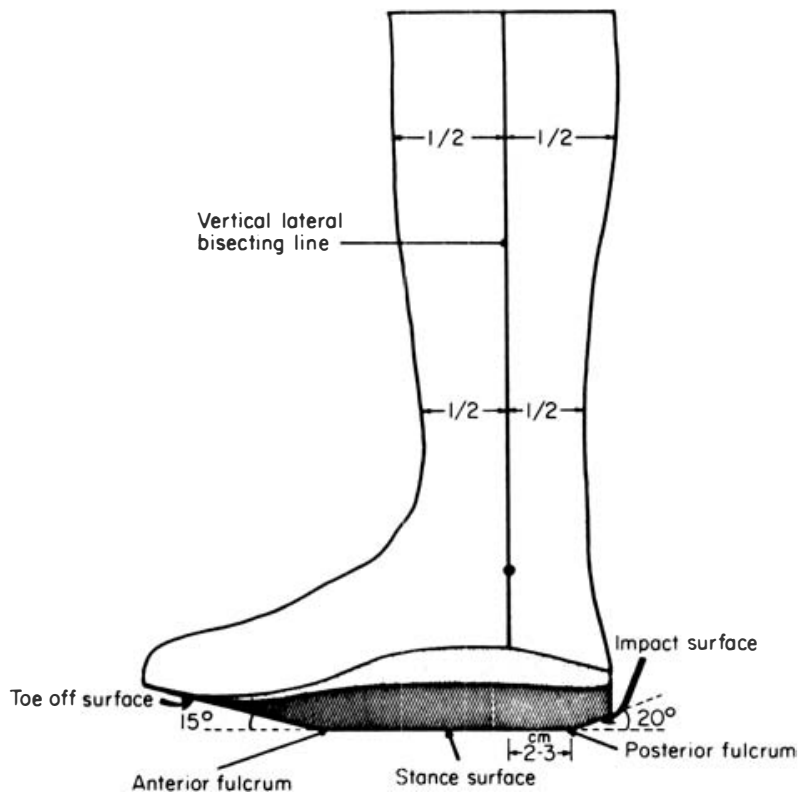

Fig. 6. A diagram of the position of the leather-and-cork insole.

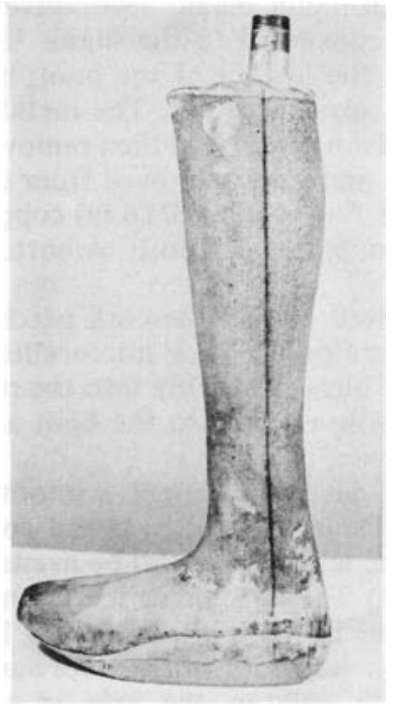

Fig. 7. A lateral view of the cast and finished insole.

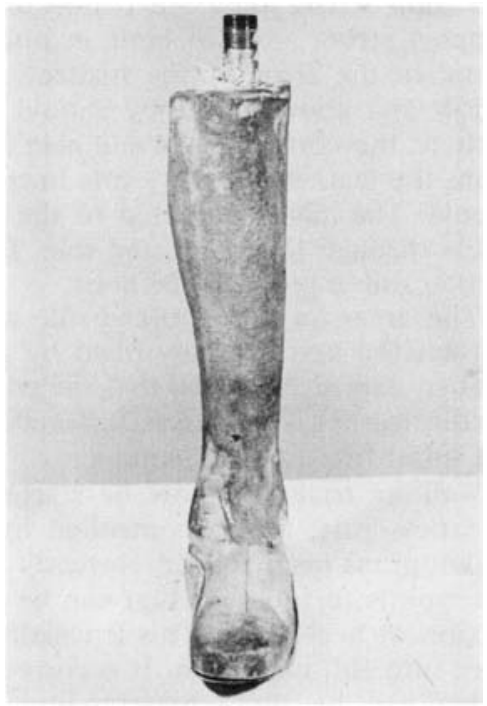

Fig. 8. An anterior view of the cast and insole ready to have the boot built over it. 


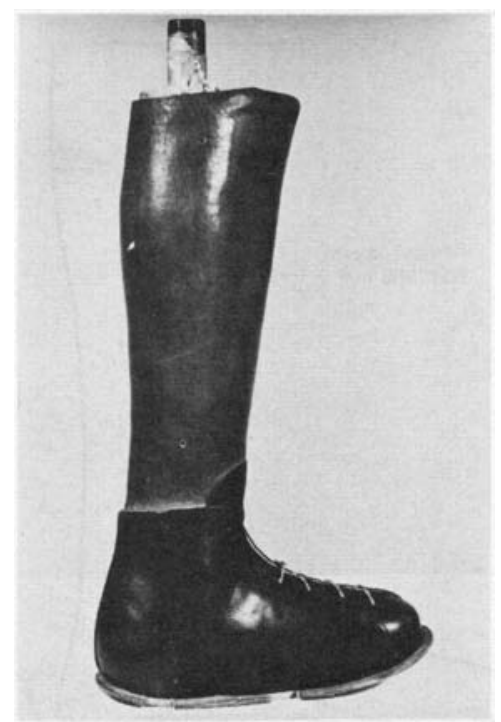

Fig. 9. The boot and gaiter ready for the fixing of the metal brace.

the boot should overlap the distal edge of the gaiter by $13 \mathrm{~mm}(1 / 2 \mathrm{in})$. If this is not done there is the likelihood that a circumferential band of oedema will form in the area of the ankle. The boot is constructed up to the welting.

The metal side-bars are made from $20 \mathrm{~mm} \times 3 \mathrm{~mm}$ mild steel strip. The vertical bars lie on both sides of the leg and the lower ends are bent in under the sole of the foot, where they are connected to a full length metal shank. Two anterior support struts are also bent in under the sole and connected to the shank. The metal in the areas of the malleoli should just clear the leather of the boot, but below and above this they should be lying snugly against leather. The metal is bent to the correct shape and held in place with rivets or bolts. It is then removed from the leather, all the joints brazed, and the boot and gaiter removed from the mould. The metal is riveted to the boot by three or four 4-mm (3/16 in) copper rivets through the shank and sole. The gaiter is held in place with bolts. A bottom leather sole is put into the boot.

The areas on the moulded sole which were hollowed out by the cork patches put on the cast are now filled by patches of 15-shore 6-mm thick microcellular rubber, care being taken that the edges of the rubber blend smoothly into the rest of the leather sole (Fig. 10). Finally, the moulded sole is put into the boot and the splint fitted to the patient.

Walking trials can now be started. The aim is to give the patient a smooth, effortless gait; this is controlled by the shape of the bottom sole. If the cork build-up has been shaped correctly very little, if any, adjustment will be needed. The points to look for that can be corrected are: (1) The knee being forced into flexion at heel-strike. This is usually compensated for by the patient locking his knee into full extension. It is corrected by moving the posterior fulcrum forward, which can be done by standing down the leather sole in the area of the impact-surface. (2) Patient not being steady at mid-stance phase. The stance-surface is not level or is at an angle so that not all of it is in contact with 


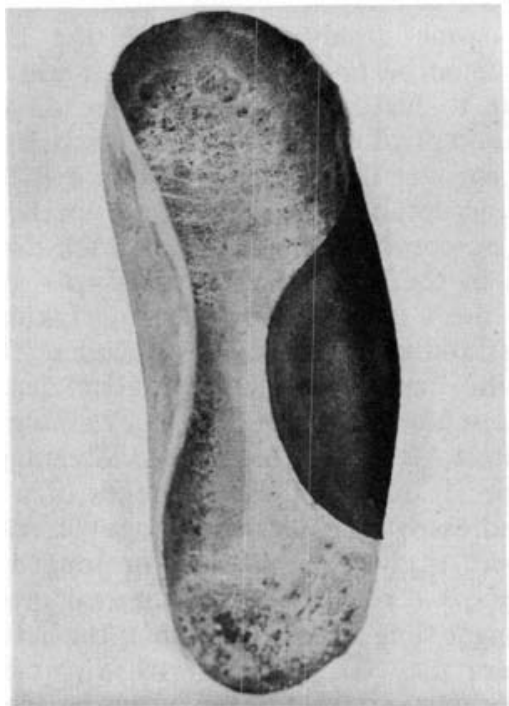

Fig. 10. The hard moulded insole with the 6-mm MCR in the danger area. The moulding in the arch can also be seen.

the ground. This is corrected by sanding down and applying leather to bring all the stance-surface into contact with the ground. (3) At heel-off the patient does not roll over the front part of the foot easily, so that the knee is forced back into extension; the patient will also bend forward at the waist in order to bring his centre of gravity further forward over the foot. This condition is caused by the anterior fulcrum being too far forward or the stance-surface being too high in the front. It is corrected by sanding down the leather sole. (4) At push-off the patient comes up on to the front section of the toe-off surface. This is due to the anterior angle being too low and the stance-surface not having been built up high enough to allow for the angle of $15^{\circ}$. Check and correct the angle of the toe-off surface. (5) The patient has a tendency to lateral instability. This condition is usually seen in a patient who has a fixed inversion of the foot. The cause is insufficient lateral build-out of the insole. At stance-phase the weight line must pass through the centre of the sole. To achieve this with an inverted foot the sole must be extended out on the lateral side; this should be done when building the cork insole. Lateral instability is difficult to correct at the fitting stage.

The patient wears the FAB walker in the fitting state for at least $8 \mathrm{~h}$. The usual care has to be taken that there are no "shoe bites" caused by the new leather. At finishing, the sole has one layer of car tyre stitched and glued to it; care must be taken that the tyre is of even thickness. The leather gaiter is finished with some type of anterior fixing, e.g. lacing, buckles and straps, or Velcro straps. The gaiter is riveted to the side bars. The FAB walker is now finished.

This design of brace sound s as if it is very cumbersome and ugly, but this is not the case at all. Cosmesis is achieved by the boot and bracer very closely fitting the patient's foot and leg so that very little extra bulk is added to the patient's deformed foot. In the case of a shortened foot the forepart of the boot is extended to give the resemblance of a full-length foot. 
There are naturally some disadvantages with the FAB walker, but while thinking about them it must be taken into consideration the limitations that the patient already has due to his deformed foot. The disadvantages are: (1) The brace and boot must be kept in good repair. (2) As it is made from leather and metal it is not suitable for wet framing, etc. (3) As it is footwear, in most Asian countries it will not be acceptable in the temple or kitchen. (4) If the patient has a plantar ulcer there is no room for bandages or thick dressings, unless space has been allowed for them in the accurately moulded sole. (5) The manufacture of the FAB walker is a fairly straightforward undertaking, but it still requires accuracy and the understanding of the basic principles. The manufacture should be entrusted only to the hands of a skilled technician. (6) The brace is not suitable for patients whose ulcers will not heal in a walking PoP cast.

On the other hand the FAB walker has several advantages, apart from keeping deformed feet ulcer-free. It has all the advantages of a PoP cast, in that it is removable-this is indeed essential for hygienic reasons. Another advantage is that the chronic ulcerated foot is given a chance of prolonged healing. This gives the surgeon an opportunity to review plans on surgical procedures. As is known, osteomyelitis needs a longer time for recovery than the actual healing of the ulcer.

The responsible patient may be supplied with a pair of additional sandals to wear for festive occasions where a full boot may not be acceptable. Other patients who are wearing sandals can be provided with a FAB walker. At the first sign of the formation of an ulcer the patient uses the brace-in other words he applies his own PoP. Such patients can also use the brace when they have long distances to walk. With the correct placement of the roll the patient's gait is nearly normal. This is regardless of muscle imbalance or muscle weakness in the foot or limited movement in joints. When a patient is wearing long trousers or a lungi it looks as if he is wearing a pair of shoes, whereas in actual fact he is wearing the equivalent of a PoP cast. As the FAB walker is made from leather and mild steel the cost is low, Rs. $30, £ 1.60, \$ 4$ for materials and $30 \mathrm{~h}$ for fabrication is all that is needed. This money and time must be compared to the full cost of treating a deformed perpetually re-ulcerating foot.

For many patients the FAB walker has broken the circle of re-ulceration and so is the essential link to his rehabilitation.

\section{Ref erences}

Bauman, J. H., Girling, J. P. and Brand, P. W. (1963). Plantar pressures and trophic ulceration. J. Bone Jt Surg. 45B, 652.

Girling, J., Hameed, M. A., Selvapandian, A. J. and Fritschi, E. P. (1967). Further advances in special footwear and moulded soles. Lepr. Rev. 38, 103.

Price, E. W. (1960). The management of plantar ulcers. Lepr. Rev. 31, 159.

Price, E. W. (1961). Plantar ulcers in leprosy. A review of the literature, Lepr. Rev. 32, 108.

Ross, W. F. (1962). Footwear and the preventioh of ulcers in leprosy. Lepr. Rev. 33, 202.

Ward, D. J. (1964). Plantar ulceration and footwear in leprosy. In Cochrane's Leprosy in Theory and Practice, p. 554, 2nd ed. John Wright and Sons, Bristol. 